\title{
Risk Identification of Water Pollution Sources in Water Source Areas of Middle Route of the South-to-North Water Diversion Project
}

\author{
Lian Sun, Meng Xu, Junxiang Jia, and Chunhui Li
}

\begin{abstract}
Water source areas are vulnerable to human's development. It is necessary to identify the risk of water pollution sources in water sources areas with a large number of industrial and agricultural enterprises. An identification model based on entropy weight method and K-Means clustering analysis was proposed to identify the level of risk of water pollution sources in the water sources are a qualitatively. Then the model was used in the case study Danjiangkou reservoir which is the water source of Middle Route of the South-to-North Water Diversion Project in China. The results show that there are nine industrial samples and two agricultural samples in the relatively high risk level which could engender high risk of water pollution to the Danjiangkou reservoir. In the end, suggestions are proposed to facilitate the management for water resources and environmental departments.
\end{abstract}

Index Terms-Clustering analysis, Danjiangkou reservoir, risk identification, water pollution.

\section{INTRODUCTION}

Water source areas are critical to human's life, production and ecological system. With the rapid development of economy and society, the water source areas suffer the risk of anthropogenic water pollution. Therefore, it is essential to identify which are the higher or highest risk that could result in environmental risk. Risk identification denotes the process that we identify or classify the properties of potential or existing risk sources and factors by using certain methods. It is the first stage of risk management and is the basic of the next steps of risk management such as analysis and control of risk management [1].

Industry enterprises are usually the largest risk sources threatening the water sources districts. Peng, Song et al. [2] focused on the three aspects of emergency water pollution: risk sources, influence range and the sensitive receptor and developed a five-step method to assess the losses from potential chemical pollution accident in industrial parks. Zhao, Qin et al. [3] assessed the emergency health risk of emergency water pollution produced by the chemical company because of the emergency accident based on

Manuscript received May 21, 2015; revised September 17, 2015. This work was supported by National Science and Technology Support Program.

Lian Sun and Chunhui Li are with the School of Environment, Beijing Normal University, Beijing 100875 China (e-mail: sl@mail.bnu.edu.cn, xumeng@zufe.edu.cn, chunhuili@bnu.edu.cn).

Junxiang Jia was with Beijing Normal University. She is now with the Minister of Water Resources, Beijing 100053 China (e-mail: jjx9009@sina.com).

Meng Xu is with the School of Urban/Rural Planning and Management of Zhejiang University of Finance and Economics, Hangzhou 310018 China. quotients method and probability distribution of quotients qualitative. At the same time, the non-pointed sources pollution is becoming the important one besides the pointed pollution. Coupled the characteristics of NPS pollution, such as stochastic, broad, fuzzy and delayed effects [4], the research of risk identification are usually operated with geographic information system (GIS) and geostatistics method. Wang, Zuo et al. [5] established identification model of critical risk source areas for agricultural non-point source pollution with multifactor analysis method based on the indexes system of GIS. USLE(Universal Soil Loss Equation) is a general used model to identify the potential risk of NPS pollution. Hu, Wang et al. [6]modified the USLE model to identify the risk area with the help of GIS in a watershed. Combined with remote sense and GIS, Yang, Xu et al. [7] developed a model considering many factors contributing to the NPS pollution and used it identify the districts suffering from potential water pollution risk.

Analyzing with multi-factors is a fundamental and most frequently used method to determine the critical risk sources. The critic problem of multi-factor analysis is to establish the index system and determine the weight of assessment indexes [8]. Entropy is a function to describe the status of a system, and it could be used to reflect the order degree of a system. Entropy is a relatively ideal tool to gauge the weight of indexes in an index system and entropy weight method has the advantage in determining the index weight objectively [9]. $\mathrm{K}$-means clustering analysis could achieve classification by assigning a set of objects into groups, called clusters, so that the objects in the same cluster are more similar. Different from other clustering methods, $\mathrm{K}$-means clustering analysis has a merit of quickly and concise algorithm. Therefore, if a water quality manager use a method that integrates the entropy weight method and $\mathrm{K}$-means clustering analysis, we would assess the risk more objectively and identify which risk sources should be paid more attention to supervise and manage.

Danjiangkou reservoir, lying in middle China, serves as the water source of Middle Route of the South-to-North Water Diversion Project which just began to transfer water to North China in the end of 2014. The aim of this project is expected to alleviate the severe water scarcity of agricultural production and sustain the increasing need of domestic department in the North China Plain. Consequently, it is of great importance to ensure the security of water quality in Danjiangkou reservoir. The issue to identify the risk of water pollution for water sources in Shiyan is proposed necessarily.

In this paper, an identification model is developed to identify the risk of water pollution sources based on the 
objective assessment method of index weight and clustering analysis method. Then the integrated method was applied to Danjiangkou reservoir as a case study to identify the risk level of water pollution sources and the distribution characteristics of these sources.

\section{MATERIALS AND METHODS}

\section{A. Overview of the Studying Area}

Shiyan district lies in the northeast of Hubei province in central China (Fig. 1). It is located in the north subtropics climate zone, with the annual average temperature of $13.7{ }^{\circ} \mathrm{C}$ and annual precipitation of $873 \mathrm{~mm}$. Precipitation varies largely among different seasons, of which more than $80 \%$ occurs from May to August. The geomorphology in the basin is absolutely dominated by mountain with great variation of altitude and steep slope. The whole topography is tilted from west to east.

Hanjiang River, the longest tributary of Yangtze River, and tributaries of Hanjiang River like Danjiang River, Duhe River, Tianhe River et, al. consist the river system of Shiyan. Danjiangkou reservoir, the water source of China'sgreatestwater diversion project, was established in 1973 by closuring the main watercourse of Hanjiang River in Danjiangkou district. The reservoir has the area of 1022 $\mathrm{km}^{2}$ covering parts of Hubei and Henan province with the storage capacity of 29 billion $\mathrm{m}^{3}$. Recent year the water quality in reservoir is in the normal level of II III yet still suffers the risk of water pollution especially the NPS pollution [5].

Shiyan district comprises of seven parts: Shiyan city, Danjiangkou city, Yunxian county, Yunxi county, Zhushan county, Zhuxi county and Fangxian county, with the whole territory of $2.4 \times 10^{5} \mathrm{~km}^{2}$ and the population of $3.5 \times 10^{6}$. Economy and society develop quickly in the study area recent year. Since most of the area is in the upstream of the reservoir, the increasingly industrial development and expanding scale of livestock and poultry breeding in Shiyan pose more and more risk on the water sources.

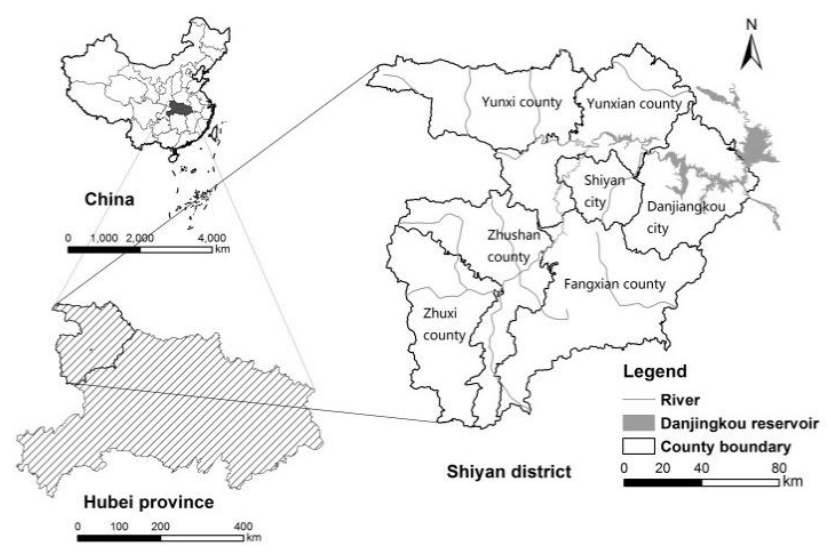

Fig. 1. The location of studying area.

\section{B. Method}

There are several kinds of perils of water pollution: traffic accident in land and water, sewage discharge of industry, and leakage of pipeline in the coast of water source areas. In recent years, the environmental department of Shiyan has taken series of strict management measures for Danjiangkou reservoir. The vessels pass the dam of Danjiangkou reservoir will be registered strictly, all the roads along the coast of the reservoir have established fences and it keeps certain distance between the fences and the canals of water diversion. With the altitude of dam was increased from $157 \mathrm{~m}$ to $170 \mathrm{~m}$, about 345,000 people were emigrated out of the reservoir area, which reduces the risk to reservoir markedly. Therefore, industrial point source pollution and agricultural non-point source(NPS) pollution, threatening water quality. Since point and non-point resource pollution have different pollution mechanism, it's essential to identify the risk level for these two respectively and select the high risk level to facilitate the water security management of a water source. As far as the study area in this paper, the water produced by livestock and poultry breeding is the absolutely dominant NPS pollution. Thus, the livestock and poultry breeding is chosen as the major target in agricultural department, ignoring others such as planting.

\section{1) Standard pollution load}

It is essential to sort out the major water pollution sources or main pollutants in a system which has more than one water pollution source and pollutant. As the amount and unit of discharge of different pollutants vary, usually it takes equal standard pollution load to standardize all the pollutants concerned.

$$
\begin{gathered}
d_{i}=q_{i} / C_{o i} \times 10^{6} \\
r_{i}=d_{i} / \sum d_{i} \times 100 \%
\end{gathered}
$$

where $d_{i}$ is the equal standard pollution load of a pollutant $\left(\mathrm{m}^{3} / \mathrm{a}\right), q_{i}$ is the discharge amount of the sewage(t/a), $C_{o i}$ is the assessment standard of $i_{t h}$ pollutant $(\mathrm{mg} / \mathrm{L}), \sum d_{i}$ is the total load of equal standard pollution $\left(\mathrm{m}^{3} / \mathrm{a}\right), r_{i}$ is the load rate of $i_{\text {th }}$ pollutant.

\section{2) Entropy weight method to calculate weights}

Entropy is a thermodynamic concept and it has been used in many domains including engineering technology and social economic. The principle of entropy weight method can be illuminated as: if the variation of an index value is larger, which means the amount of information of the index is richer and functions better in the comprehensive assessment as well as a larger entropy value and bigger weight [10]. Here is the operation steps of entropy weight method.

Assuming that there are $\mathrm{s}$ assessment indexes and $\mathrm{t}$ assessment samples, which constitutes a decision-making matrix $A$. Then we get the matrix $D_{i}$ by standardizing matrix A:

$$
D_{i}=\left[\begin{array}{ccc}
d_{11} & \cdots & d_{1 s} \\
\vdots & \ddots & \vdots \\
d_{t 1} & \cdots & d_{t s}
\end{array}\right]
$$

$$
d_{i j} \in[0,1](i=1,2, \cdots, t ; j=1,2, \ldots, s)
$$

Then the entropy of $j_{t h}(j=1,2, \ldots, s)$ index is defined as:

$$
E_{j}=-k \sum_{i=1}^{t} f_{i j} \ln f_{i j}, j=1,2, \cdots, s
$$


where $f_{i j}=d_{i j} / \sum_{i=1}^{t} d_{i j}, j=1,2, \cdots, s$, and if $f_{i j}=$

0 , fijln $i j=0, k=1 / \ln t$

And the entropy weight can be calculated:

$$
w_{j}=\left(1-E_{j}\right) / \sum_{j=1}^{s}\left(1-E_{j}\right), j=1,2, \cdots, s
$$

\section{3) K-means clustering analysis}

K-means clustering analysis was proposed by J. B. Macqueen to process the problem of clustering of data [11]. Now it is a widely used clustering analysis method because of its high efficiency and concise algorithm. This algorithm is a process that splits the data into $\mathrm{K}$ clusters according to a distant function after having determined the data set and center value of cluster $\mathrm{K}$. In this paper the comprehensive assessment values $Q_{i}$ are the process data which could be computed as:

$$
Q_{i}=\sum_{j=1}^{s} w_{i j} \times d_{i j}
$$

Here are the detail steps of the K-means clustering analysis.

Firstly we set $k$ data as the initial cluster centers stochastically $\left(m_{1}, m_{2}, \ldots, m_{k}\right)$. The value set is relative to how many grades we plan to split.

Then each $Q_{i}$ was divided into its nearest initial center, and a cluster center and its data are constituted as a cluster.

And based on the data divided into the cluster, each initial cluster center will recalculate the new cluster center $m_{i}(7)$. This step is also called iteration.

$$
m_{i}=\frac{1}{N_{i}} \sum_{j=1}^{N_{i}} Q_{i j}, i=1,2, \ldots, k
$$

where $N_{i}$ means there are $N_{i}$ data in the cluster center $m_{i}, Q_{i j}$ means the $j_{t h}$ data in cluster center mi.

The iteration will be proceeded until it satisfies the termination condition that $J(8)$, the sum of square error, is convergent. Therefore we can get the finally cluster centers $\left(m_{1}, m_{2}, \ldots, m_{k}\right)$.

$$
J=\sum_{i=1}^{k} \sum_{j=1}^{N_{i}}\left|Q_{i j}-m_{i}\right|^{2}
$$

\begin{tabular}{|c|c|c|c|c|c|}
\hline \multicolumn{2}{|r|}{ Type } & 2009 & 2010 & 2011 & 2012 \\
\hline \multirow{2}{*}{ Hog } & in stock & 152.28 & 166.76 & 181.11 & 209 \\
\hline & output stock & 150.66 & 160.75 & 170.25 & 180.81 \\
\hline \multirow{2}{*}{$\begin{array}{c}\text { Cattle } \\
\text { and } \\
\text { buffaloes }\end{array}$} & in stock & 26.2 & 28.4 & 31.96 & 37.07 \\
\hline & output stock & 6.06 & 7.66 & 9.67 & 10.1 \\
\hline \multirow{2}{*}{ Sheep } & in stock & 68.92 & 75.26 & 84.16 & 97.44 \\
\hline & output stock & 66.37 & 77.32 & 90.05 & 92.75 \\
\hline \multirow{2}{*}{ Poultry } & in stock & 1403.23 & 1675.46 & 1535.75 & 1941.19 \\
\hline & output stock & 1669.72 & 2254.12 & 2333.01 & 2832 \\
\hline
\end{tabular}

\section{4) Livestock and poultry breeding analysis}

Note: the amount in stock is in the end of a year.

The livestock and poultry in stock and output of stock were aggregated according to the statistical yearbook of Shiyan from 2009 2012 (Table I). Coupled with manure and urine

\begin{tabular}{|c|c|c|c|c|c|}
\hline \multicolumn{6}{|c|}{ AND POULTRY } \\
\hline & \multirow{2}{*}{$\begin{array}{c}\text { Cattle } \\
\text { and } \\
\text { buffaloes }\end{array}$} & \multirow[b]{2}{*}{ Hog } & \multirow{2}{*}{ Sheep } & \multirow{2}{*}{$\begin{array}{c}\text { Poultry in } \\
\text { stock }\end{array}$} & \multirow{2}{*}{$\begin{array}{l}\text { Poultry out } \\
\text { stock }\end{array}$} \\
\hline & & & & & \\
\hline Manure & 25 & 2.5 & 1.5 & 0.15 & 0.11 \\
\hline Urine & 10 & 3 & 0.5 & 0.15 & 0.11 \\
\hline $\begin{array}{c}\text { Breeding } \\
\text { period }\end{array}$ & 365 & 180 & 365 & 365 & 90 \\
\hline
\end{tabular}

generation coefficient of livestock and poultry (Table II), the total manure and urine could be estimated.

TABLEII: MANURE AND URINE GENERATION COEFFICIENT OF LIVESTOCK

\section{RESULTS AND DISCUSSION}

\section{A. Industrial Risk}

Building brick manufacturing, auto and auto parts manufacturing, metal processing and manufacturing, mining and dressing are the four main industries in Shiyan which account for the $80 \%$ companies .

Discharge quantity of sewage, Discharge concentration of industrial source, Discharge rate of sewage, Industry category and Distance to the reservoir were selected as the five risk identification indexes of industrial risk. COD, $\mathrm{NH}_{3}-\mathrm{N}$, petroleum, volatile phenol, cyanide, As, total $\mathrm{Cr}$, $\mathrm{Cr}^{6+}, \mathrm{Pb}, \mathrm{Cd}, \mathrm{Hg}$, all this eleven indexes were selected as the second level index of Discharge concentration of industrial sources, according to the table of risk identification indexes of industrial sewage and discharge situation of water pollutant in Shiyan.

There are 292 industrial company samples, numbered as P1, P2, .., P292, that could be the risk sources to the Danjiangkou reservoir in Shiyan. By standardizing pollution load and calculating the entropy of all the samples, we can get the weights of these indexes: 0.0393, 0.0601, 0.0605, 0.1091, $0.1001,0.1025,0.1123,0.1135,0.0943,0.1062$ and 0.1021 respectively. By weighted average of these eleven indexes, the weighted of the first level index Discharge concentration of industrial source was generated (the third column in Table III except its first value).

So operated as the index Discharge concentration of industrial source, the other four risk identification indexes of industrial risk can be calculated (Table III).Through weighted average, we can get comprehensive assessment value $Q_{i}$ of each industrial sample. The detail weights and value of $Q_{i}$ are displayed in Table III

When the number of initial cluster center was set as 3 , all the data were classified into their own cluster by using $\mathrm{K}$-means clustering analysis. The result shows that there are nine pollution sources in the high cluster level 2 or 3 , other 283 sources are in low cluster level 1 . That means that most likely pollution sources are low risk of water pollution, only about $3 \%$ of the sources are high risk of water pollution.

According to the result of K-means clustering analysis, the point P40, P64, P128, P134, P138, P144, P145, P171 are in the relatively high risk level, and $\mathrm{P} 89$ is the only one point in the high risk level. On one hand, among these relatively high risk pollution sources, three of which (P134,P45,P171) are mining and dressing, two(P128,P138) are metal smelting, others are plastic manufacturing, thermal power, auto refitting, and plastic manufacturing(Table IV). On the other hand, if projecting them into the map, we can easily find out 
where the different risk level sources are located (Fig. 2). There are four points (P128, P138, P144, P145) lying in the coast of Tianhe River, a tributary of Danjiangkou reservoir; and the point P89, the highest risk level one, just lies in the coast of Danjiangkou reservoir. Additionally, five sources are in Yunxi lying in the upstream of Shiyan. These remind the water security managers that they should take more attention to the mining and dressing, metal smelting or the point P89 to reduce the risk of water pollution. At the same time, managers should focus on some tributaries, especially on the Tianhe River, and on certain district like Yunxi county. Other industries and districts should also be considered.

TABLEIII: THE IDENTIFICATION RESULTS OF INDUSTRIAL RISK

\begin{tabular}{|l|l|l|l|l|l|l|l|}
\hline Point & $\begin{array}{l}\text { Discharge quantity } \\
\text { of sewage }\end{array}$ & $\begin{array}{l}\text { Discharge concentration } \\
\text { of industrial source }\end{array}$ & $\begin{array}{l}\text { Discharge rate } \\
\text { of sewage }\end{array}$ & $\begin{array}{l}\text { Industry } \\
\text { category }\end{array}$ & $\begin{array}{l}\text { Distance to the } \\
\text { reservoir }\end{array}$ & $\begin{array}{l}\text { Comprehensive } \\
\text { assessment } \\
\text { value/Qi }\end{array}$ & $\begin{array}{l}\text { K-means } \\
\text { clustering }\end{array}$ \\
\hline weight & 0.2523 & 0.4567 & 0.1138 & 0.0938 & 0.0834 & 0.0357 \\
\hline P40 & 0.0001 & 0.0752 & 0.0058 & 0.0060 & 0.0014 & 0.0240 \\
\hline P64 & 0.0908 & 0.0000 & 0.0001 & 0.0060 & 0.0058 & 2 \\
\hline P89 & 0.0000 & 0.2156 & 0.0004 & 0.0000 & 0.0005 & 0.0986 \\
\hline P128 & 0.0211 & 0.0943 & 0.0082 & 0.0060 & 0.0025 & 0.0501 \\
\hline P134 & 0.0010 & 0.0432 & 0.0022 & 0.0119 & 0.0051 & 0.0218 \\
\hline P138 & 0.0010 & 0.0713 & 0.0037 & 0.0119 & 0.0061 & 0.0349 \\
\hline P144 & 0.0005 & 0.0717 & 0.0005 & 0.0000 & 0.0025 & 2 \\
\hline P145 & 0.0002 & 0.1283 & 0.0013 & 0.0119 & 0.0023 & 2 \\
\hline P171 & 0.0128 & 0.0599 & 0.0060 & 0.0067 & 0.0601 \\
\hline
\end{tabular}

Note: Discharge concentration of industrial source refers to the discharge concentration of $\mathrm{COD}, \mathrm{NH}_{3}-\mathrm{N}$, petroleum, volatile phenol, cyanide, As, total Cr, $\mathrm{Cr}^{6+}, \mathrm{Pb}, \mathrm{Cd}, \mathrm{Hg}$; Discharge rate of sewage = Discharge quantity of sewage / Production quantity of sewage.

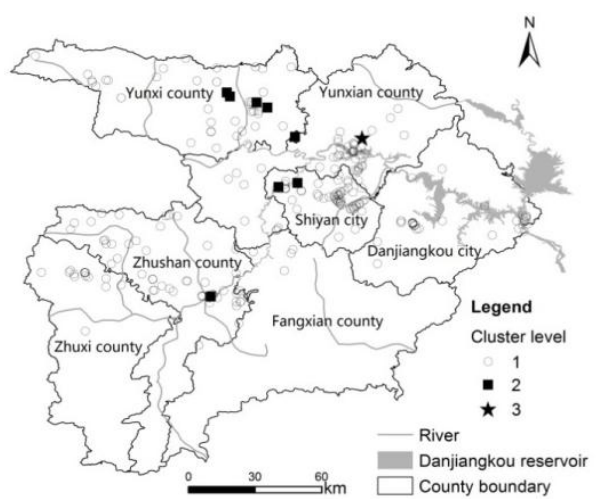

Fig. 2. Clustering results of industrial pollution sources risk identification Note: several points overlap others for the limitation or the extension of the map.

TABLE IV: CLUSTERING RESULTS OF INDUSTRIAL RISK

\begin{tabular}{|l|c|l|l|l|}
\hline Point & $\begin{array}{c}\text { Cluster } \\
\text { level }\end{array}$ & Location & Industrial sector & $\begin{array}{l}\text { Receiving } \\
\text { water body }\end{array}$ \\
\hline P40 & 2 & $\begin{array}{l}\text { Zhangwan } \\
\text { district }\end{array}$ & $\begin{array}{l}\text { Specialized } \\
\text { chemical products } \\
\text { manufacturing }\end{array}$ & Jianghe River \\
\hline P64 & 2 & $\begin{array}{l}\text { Zhangwan } \\
\text { district }\end{array}$ & Thermal power & $\begin{array}{l}\text { Hongweihe } \\
\text { River }\end{array}$ \\
\hline P89 & 3 & Yunxian & Auto refitting & $\begin{array}{l}\text { Danjiangkou } \\
\text { reservoir }\end{array}$ \\
\hline P128 & 2 & Yunxi & Puddling & Tianhe River \\
\hline P134 & 2 & Yunxi & $\begin{array}{l}\text { Antimony ore } \\
\text { processing }\end{array}$ & Xianhe River \\
\hline P138 & 2 & Yunxi & Antimony dressing & Tianhe River \\
\hline P144 & 2 & Yunxi & $\begin{array}{l}\text { Plastic } \\
\text { manufacturing }\end{array}$ & Tianhe River \\
\hline P145 & 2 & Yunxi & $\begin{array}{l}\text { Lead and zinc ore } \\
\text { dressing }\end{array}$ & Tianhe River \\
\hline P171 & 2 & Zhushan & Silver dressing & Duhe River \\
\hline Others & 1 & - & - & - \\
\hline
\end{tabular}

\section{B. Agriculture Risk}

The amount of manure and urine of livestock and poultry in Shiyan district can be estimated by multiplying the data in Table I and Table II. As is shown in Table V, the total amount of manure produced by the five main kinds of livestock and poultry is 6645702 ton, and the urine is 4806564 ton.

NPS pollution produced by poultry breeding and livestock and is affected by a variety of factors, such as the amount of manure and urine of animal, the distance from the water area for the polluted land, and the characteristics of precipitation and land use et al. Thus, referring to the exiting information, Breeding scale, Producing amount of manure, Producing amount of urine, Discharge rate of pollutants were selected as the four risk identification indexes of industrial risk. Breeding scale of a livestock or poultry denotes the rate that the amount of a livestock or poultry is divided by its standard value of scale. The breeding scale of different livestock or poultry varies: hog is divided by 500 , dairy cattle by 100 , beef cattle by 200 , Poultry for meat by 20,000 , Poultry for eggs by 50,000 [12].

TABLEV: MANURE AND URINE GENERATION OF LIVESTOCK AND POULTRY BREEDING IN SHIYAN

\begin{tabular}{|l|l|l|l|}
\hline $\begin{array}{l}\text { Livestock or } \\
\text { poultry }\end{array}$ & $\begin{array}{l}\text { Scale } \\
\left(\times 10^{4}\right)\end{array}$ & $\begin{array}{l}\text { Producing of } \\
\text { manure(ton) }\end{array}$ & $\begin{array}{l}\text { Producing of } \\
\text { urine(ton) }\end{array}$ \\
\hline Hog & 351.36 & 1581120 & 1897344 \\
\hline Cattle & 41.63 & 3038990 & 1519495 \\
\hline Sheep & 174.21 & 953800 & 317933 \\
\hline Poultry for meat & 1535.75 & 840824 & 840824 \\
\hline Poultry for eggs & 2333.01 & 230968 & 230968 \\
\hline Sum & - & 6645702 & 4806564 \\
\hline
\end{tabular}

There are 65 agriculture NPS pollution samples, numbered as L1, L2, ..., L65. Based on the data in Table V, standard pollution load and the entropy weight of these four indexes (Breeding scale, Producing amount of manure, Producing amount of urine, Discharge rate of pollutants) were conducted successively. After acquiring the comprehensive value $Q_{i}$ and setting the cluster center as 2 , we could identify all the 65 data into their cluster level. The results show that there are only two points in the second risk level representing high risk of water pollution and other 63 points are in relatively low risk (Table VI).

Point L23 is an animal husbandry company located in the Yunxian county with the distance of 1.5 kilometers to the main stream of Hanjiang River. The company covers an area of $45 \mathrm{~km}^{2}$, ranking to the company covering the largest area among all the 65 agricultural companies. L54 is a company whose business scope embraces poultry, cultivating of vegetable, fruit, flowers, et, al. It locates in the Langhe River, a tributary of Danjingkou reservoir. It covers an area of 5.86 $\mathrm{km}^{2}$, much smaller than L23. However, the comprehensive assessment value of L54 is larger than L23, which shows the 
risk level of L54 is higher. Both of these two companies are not far from the reservoir. Thus the managers should take care of their potential pollution threaten to Danjiangkou reservoir.

TABLE VI: THE IDENTIFICATION RESULTS OF AGRICULTURAL RISK

\begin{tabular}{|l|l|l|l|l|l|}
\hline Point & Breeding scale & Producing amount of manure & Producing amount of urine & $\begin{array}{l}\text { Discharge rate of } \\
\text { pollutants }\end{array}$ & $\begin{array}{l}\text { Comprehensive } \\
\text { assessment } \\
\text { value } \mathrm{Q}_{\mathrm{i}}\end{array}$ \\
\hline Weight & 0.3081 & 0.3669 & 0.2805 & 0.0444 & \\
\hline L23 & 0.0537 & 0.2547 & 0.1118 & 0.0046 & 0.1416 \\
\hline L54 & 0.2686 & 0.1570 & 0.2067 & 0.0123 & 2 \\
\hline
\end{tabular}

\section{CONCLUSION}

Combined with standard pollution load, the K-means clustering analysis method was conducted to identify the water pollution risk for Shiyan district where it is the water resource of China's Middle Route of the South-to-North Water Diversion Project. All the 192 industrial risk sources and 65 agricultural risk sources were evaluated respectively and the weights of which were calculated. Consequently we can identify which are in the higher ranks represented by the higher cluster center numbers. By analyzing the attribute of these higher points and checking their spatial distribution, we concluded some useful findings.

There are 9 industrial companies are in the higher risk level 2 or 3 . These companies usually belong to industrial sector of mining and dressing, metal smelting. Four companies of these nine are established in the coast of rivers and the only one company in the highest risk is lying to the Danjiangkou reservoir. The Yunxi county owes most of these high risk companies.

There are 2 agricultural companies are in the higher risk level 2. One is an animal husbandry company lying the Yunxian county, and the other conducts producing of poultry, cultivating of vegetable, fruit, flowers, et, al. Both of them are covers larger area than industrial companies and have the risk of nonpoint water pollution. And these two companies are not situated far from the reservoir, which poses relatively high water pollution risk to the Danjiangkou reservoir.

These remind the water security managers that they should take more attention to certain industrial sector like the mining and dressing, metal smelting or certain point like P89 to reduce the risk of water pollution. At the same time, managers should focus on some tributaries, especially on the Tianhe River, and on certain district like Yunxi county. Regarding the agricultural companies, the managers in Shiyan should pay more attention to several companies like L23 and L54 since they are not far from the reservoir and have the highest risk level. Other industries and districts and the agriculture companies should also be considered.

\section{ACKNOWLEDGMENT}

This study was supported by the National Science and Technology Support Program (No. 2011BAC12B02).

\section{REFERENCES}

[1] L. Tchankova, "Risk identification basic in risk management," Environmental Management and Health, vol. 13, pp. 290-297, 2002.

[2] J. F. Peng et al., "An novel identification method of the environmental risk sources for surface water pollution accidents in chemical industrial parks," J Environ Sci, vol. 25, pp. 1441-1449, 2013.

[3] Y. M. Zhao et al., "Emergency health risk assessment of water pollution accident," China Environmental Science, vol. 34, pp. 1328-1335, 2014.

[4] C. Lu, H. Y. Zhang, and L. Qi, "Critical source area identification and risk assessment of agricultural non-point source pollution of the source areas of Liaohe river watershed," Acta Agriculturae Universitatis Jiangxiensis, vol. 36, pp. 670-677, 2014

[5] G. Q. Wang, H. F. Zuo, J. H. Wei, and Y. F. Huang, "Identifying critical source areas for agricultural non-point source pollution in Laoguanhe watershed of middle route of the south-to-north wate diversion project," Earth Science Frontiers, vol. 17, pp. 13-20, 2010.

[6] L. W. Hu et al., "GIS based identification of potential risk areas of non-point source pollution in hangbu-fengle watershed," Bulletin of Soil and Water Conservation, vol. 27, pp. 107, 2007.

[7] F. Yang, Z. C. Xu et al., "Evaluation of agricultural nonpoint source pollution potential risk over China with a transformed-agricultural nonpoint pollution potential index method," Environmental Technology, vol. 34, pp. 2951-2963, 2013.

[8] H. P. Zhou, C. Gao, and X. D. Zhu, "Identification of critical source areas: an efficient way for agricultural nonpoint source pollution control," Acta Ecologica Sinica, vol. 25, pp. 3368-3374, 2005.

[9] J. L. Wu et al., "Application of variable fuzzy set theory method based on entropy weight to evaluation Water pollution," Mathematics in Practice and Theory, vol. 42, pp. 65-73, 2012.

[10] Z. H. Zou, J. N. Sun, and G. P. Ren, "Study and application on the entropy method for determination of weight of evaluating indicators in fuzzy synthetic evaluation for water quality assessment," Acta Scientiae Circumstantiae, vol. 25, pp. 552-556, 2005.

[11] J. B. Macqueen, "Some methods for classifieation and analysis of multivariate observation," in Proc 5th Berkeley Symp Math Statist. Berkeley, USA: University of California Press, 2000, pp. 281-297.

[12] Q. Y. Wu, "Breeding of large scale waterfowl and its measures of energy conservation and emission reduction," The World of Waterfowl, vol. 21, pp. 7-9, 2012.

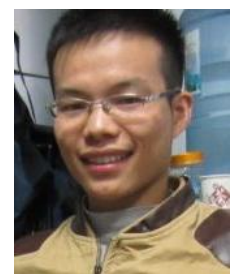

Lian Sun was born in Qimen, Anhui province, China He obtained a bachelor degree of geography in Anhui Normal University. Now, he is a graduated student majoring in hydrology and water resources in the School of Environment, Beijing Normal University, Beijing, China.

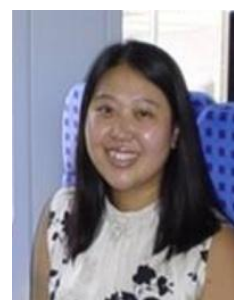

Meng Xu was born in Taiyuan, Shanxi province, China. She received her master degree of enviromental and resource management in Brandenburg University of Technology, Cottbus, in 2006 in Germany. Currently, she is a lecturer in School of Urban/Rural Planning and Management in Zhejiang University of Finance and Economics, majoring in water resource management. Since 2013, she has been the doctorial candidate in the School of Environment, Beijing Normal University, majoring in water resource management and allocation.

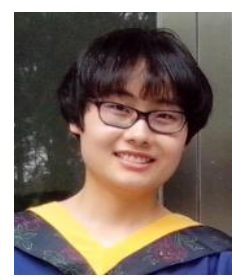

Junxiang Jia was born in Dezhou, Shandong province, China. She earned her degree of master of hydrology and water resources from Beijing Normal University, Beijing China, 2014. Now she is working in the Ministry of Water Resources of P. R. China.

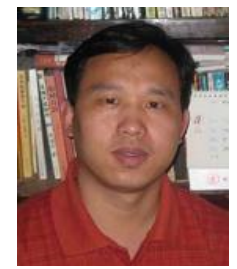

Chunhui Li was born in Linquan, Anhui province, China. He received his Ph.D degree from Beijing Normal University, China, and did research as a post-doctor in Regina University, Canada. Now he is an associated professor doing research in water resources assessment and planning and environmental influence assessment in the School of Environment, Beijing Normal University. 